University at Buffalo School of Law

Digital Commons @ University at Buffalo School of Law

Journal Articles

Faculty Scholarship

$11-1-1987$

\title{
Getting to Solla Sollew: The Existential Politics of Dr. Seuss
}

Elizabeth B. Mensch

University at Buffalo School of Law

Alan David Freeman

University at Buffalo School of Law

Follow this and additional works at: https://digitalcommons.law.buffalo.edu/journal_articles

Part of the Law and Politics Commons

\section{Recommended Citation}

Betty Mensch \& Alan Freeman, Getting to Solla Sollew: The Existential Politics of Dr. Seuss, Tikkun, Nov. 1987, at 30.

First published in Tikkun-a Jewish and intefaith prophetic voice for a world of justice and love.

C. IN COPYRIGHT

This Article is brought to you for free and open access by the Faculty Scholarship at Digital Commons @ University at Buffalo School of Law. It has been accepted for inclusion in Journal Articles by an authorized administrator of Digital Commons @ University at Buffalo School of Law. For more information, please contact lawscholar@buffalo.edu. 


\title{
Getting to Solla Sollew: The Existential Politics of Dr. Seuss
}

\author{
Betty Mensch and Alan Freeman
}

$\mathbf{I}$ n early 1986, there appeared in the world a book of forty-two (unnumbered) pages, written in rhythmically repetitive and meticulously rhymed simplistic verse which some would call doggerel. Every page is illustrated in bright colors, with large and fanciful cartoon characters. One is a friendly, sympathetic goldfish named Norval. The story is about the awful experience of going to the doctor for a checkup, but the experience is made less threatening through the author's mode of silly exaggeration.

This format and story line suggest a children's book, one fairly typical of the genre. In fact, however, the book is You're Only Old Once, by Theodore Seuss Geisel, also and usually known as Dr. Seuss, and its intended audience is grown-ups, especially the elderly. However improbable the idea of writing a children's book for grown-ups, on March 8, 1987, the book celebrated a full year on the New York Times Best Seller List. As recently as February 22, 1987, it was number four on the list.

This success should not be surprising. Dr. Seuss merely employed the form that has over the past fifty years made him one of the most successful writers of children's literature in the history of the English language, ranking him with such as Lewis Carroll or Beatrix Potter. He has sold more than one hundred million books. What worked for his elderly audience has been working for children all along.

What the snobbish may dismiss as Dr. Seuss's doggerel is an incessant, bouncy anapestic rhythm punctuated by lively, memorable rhymes. In opposition to the conventional-indeed, hegemonic-iambic voice, his metric triplets offer the power of a more primal chant which quickly draws the reader in with its relentless repetition. Moreover, what seems to be the silly whimsy of his books - the made-up words, the outlandish creatures and machines - carries an empowering message. Seuss is a smasher of conventional boundaries. He invents his own words, defying the language/

Alan Freeman and Betty Mensch are, collectively, parents of Jonathan (17), Jennifer (17), Joshua (16), James (3), and Jeremy (1). They are also both professors of Law at the State University of New York at Buffalo. For their valuable suggestions, the authors are grateful to Barry Boyer, David Fraser, Isabel Marcus, and Victor Thuronyi. nonsense boundary; he invents his own creatures, defying the human/animal boundary; he is unceasingly sarcastic and satirical yet profoundly serious, ultimately defying the boundary between what is serious and what is absurd.

This form reaches the powerless, such as small children and old people, who are expected to be passive and are objectified through their nonconsensual submission to authority. For such readers (or, listeners, in the case of the children), the books offer a discourse of resistance; they are accessible, easily consumed, and utterly irreverent. Their suggestion that categories need not be taken for granted is empowering to those who are told they have no choice, that that's the way things are, that "life is like that."

The amazing success of You're Only Old Once is an obvious tribute to the magic of Dr. Seuss. For those of us familiar with the magic, it was no surprise. We knew that there was something special and appealing in the children's books, not just in the cuteness of the lines but in their at-least-as-serious-as-funny treatment of underlying themes and issues. Wc wrote this essay to offer our sense, through the lens of our now aging yet still resolute 1960 s political consciousness, of the profoundly existential political world of Dr. Seuss.

Empowerment is the core theme in Dr. Seuss, for with all of his irreverent nonsense he offers readers a space within which they can search for both identity and virtue, free from the oppressive force of authority and orthodoxy. Seuss develops this theme with surprising richness and complexity. Described thematically (rather than chronologically), he starts by exploring the child's struggle to achieve identity in the family, with its conventional norms of behavior and its demand for passive compliance with authority. Seuss moves from there to a description of the need for authentic, existential struggle in the world generally. He then explores quite specific forms of oppression in the modern world-hierarchy, racism, environmental devastation, and militarism-and all the suffocating ideological forms which are used to justify them. Finally, Seuss suggests the possibility of moral and political transformation. This transformation requires the creation of new selves, liberated from orthodox assumptions about scientific truth, gender, and the limited range of moral 
choice in the world. So transformed, we might even become open to the experience of forming an authentic community, in which virtue and authority are no longer at odds with each other, but reunited in new conditions of freedom.

In our world, especially in its public realm, we experience authority as disconnected from virtue. Virtue means the possibility of living a moral life; authority is what obliges us to conform to social or, more exactly, legal norms. Virtue, for most of us, means personal morality that is subjective and privatized. Authority means the state or one of its disciplinary agents. There have been times in our history, however, when it was imagined that virtue and authority might reside in the same place. Such was the claim of medieval monarchy, which supposes itself divinely sanctioned. In contrast, the modern secular state merely enforces an aggregate of subjective political choices. There remains, however, one realm in our contemporary experience where the two still purport to be united: the role of the parent. To empower children in their own quest for virtue inevitably means subverting the role of the parent. Therefore, a description of Dr. Seuss's work properly starts with his lively family psychodrama, The Cat in the Hat.*

I $\mathrm{n}$ The Cat in the Hat, with the simple elegance of a 220-word vocabulary, Seuss depicts in powerful symbolic form the core childhood dilemma of identity and authority within the family. The (nameless) narrator is a boy-the archetypal male child seeking to define himself in relation to his mother and also in relation to both conventional morality and his own chaotic, anarchic impulses. Thus the book is quite specifically about boybood, and the male quest for self-definition in the nuclear family of the 1950 s, when mother was the most powerful repressive presence in the family and the most immediate representative of convention. (It is a testament to the power of gender in that culture-and also in the traditional Freudian version of childhood-that The Cat in the Hat would be a very different book if written about a girl.)

At the start of the book the narrator and his sister, Sally, are alone and bored at home on a cold, rainy day, accompanied only by their fish in a bowl, when a loud bump suddenly announces the unexpected arrival of the slyly grinning Cat in the Hat. This cat promises "lots of good fun that is funny," and quickly dismisses the fish's strident objection that the children must not let the cat in when their mother is away:

\footnotetext{
*For a similar reading of The Cat in the Hat, stressing its psychodramatic and anti-authoritarian qualities, see chapter six of Down the Rabbit Hole, by Selma Lanes (1971).
}

But our fish said, "No! No! Make that cat go away! Tell that Cat in the Hat you do NOT want to play. He should not be here. He should not be about.

He should not be bere when your mother is out!"

The cat insists that the children should "Have no fear!" and repeats his promise that "we can bave lots of good fun ..." This he then demonstrates with his first game, a complex juggling trick that begins with the fish being tossed high in the air. After this balancing act collapses, the fish once again scolds the cat and orders him out. The cat refuses to leave, instead summoning two nameless things from a red box, thing one and thing two, who are strange, soulless, golem-like creatures resplendent in their perfect amorality. Once released, the things enter into a chaotic frenzy of unrestrained play. Like demon spirits from an animalistic id, the things run wild, wreaking havoc and even violating the absent mother's most intimate realm:

\section{On the string of one kite \\ We saw mother's new gown! \\ ber gown with the dots \\ That are pink, white and red. \\ Then we saw one kite bump \\ On the bead of ber bed!}

Just as the children are becoming nervous at the extent of the destruction, the fish, quaking with fear, announces that mother is home. Finally frightened, the narrator seizes the things and orders the cat to take them away. As the fish laments the awesome mess left in the house, the cat returns with a magic machine and restores order. When mother does return, and asks what the children did, they are uncertain what to tell her. Then, in the last two lines of the book, another voice asks us all a dreadful question: "What would you do if your mother asked you?"

\section{Dr. Seuss pusbes beyond conven- tional liberal cliché to offer a more radical version of both the problems and the likelibood of their eventual solution.}

The children are thus confronted with powerful cultural images. The fish, with his incessant scolding, articulates all the socially constructed norms defining what good little children should do, norms which parents systematically and unreflectively instill in their children. Drawing on old Christian symbolism (the fish was an ancient sign of Christianity), Dr. Seuss portrays the fish 
as a kind of ever-nagging super-ego, the embodiment of utterly conventionalized morality. Thus, as if under seige by Nietzsche himself, the fish scolds, frets, chastises, and tries to induce anxious fear of authority, but unlike the cat, he can attract the children with no independent power of his own, and his demands are designed to make the children utterly passive. The fish would have them just, "sit, sit, sit, sit." Therefore, Dr. Seuss is merciless in his mockery of the fish and the conventionality the fish represents. In the hands of the cat (his natural predator) the fish is subjected to madcap, slapstick violence-he is balanced on the cat's umbrella, dropped into a teapot, and dangled from the lines of a kite.

With all of his elaborate (and not always successful) juggling tricks, the cat seems to act as a kind of mediator: However irreverent, he complies with social norms at least enough to avoid dreaded punishment (he does clean up his mess), while at the same time retaining his utter commitment to having fun. Unlike the accomodationalist ego of Freudian imagery, however, the cat is more liberator than integrator, too much a fierce deconstructor of norms to be content with mere balancing. With his magical, prescientific technology and his offer of unrestrained fun without accountability, he is the most destabilizing character in the story. The cat has long served in Western culture as an embodiment of magical, even satanic forces. Here the cat carries on that tradition by demonstrating to the boy narrator a possibility of powerful action in the world, action unconstrained by the fish's fearful anxiety and obsession with propricty.

$I$ Had Trouble in Getting to Solla Sollew also explores the theme of action and self-definition, but here the arena of struggle is the world at large, beyond the family, where a young hero-again, a nameless male narrator-must forge his identity in the face of "a sea of troubles." In a text that resonates with the classic Man's Fute, by Malraux, Seuss suggests that neither utopian self-delusion nor foolish escapism can neutralize the need for day-to-day existential struggle. Solla Sollew is a parable of innocence and experience, of paradise lost and never regained. Its nameless protagonist starts out "real bappy and carefree and young," in a place where "notbing, not anything went wrong." By the second page, however, this poor lad has already stubbed his toe and sprained his main tailbone. Now having experienced trouble for the first time, he tries to persuade himself that if he keeps his eyes straight ahead, he'll "keep out of trouble forever." He quickly learns, however, that it is foolish to think that one can overcome troubles by merely looking out for them (i. e., by passive avoidance). Whatever direction you're looking in, our poor hero discovers, they'll get you from another one, as in rapid succession various troubles bite his tail, sting his neck, and chew on his toes.

Mightily discouraged, the gullible protagonist is taken in by the promise of utopian escapism, as a chap driving a one-wheeler, camel-pulled wubble pledges to deliver him to the "City of Solla Sollew, / On the banks of the beautiful River Wab-Hoo, / Where they never bave troubles! At least, very few." At that point our happy pilgrim jumps aboard for his brief (as he anticipates) trip to the Promised Land. The journey proves perilous, however, as nature and society both reveal a dark and sinister side. Disease soon strikes the camel, so that the once stalwart puller must now be pulled along a steep and tortuous path. Before long the bedraggled hero finds himself doing all the pulling while his supposedly generous wubble-owning companion rides beside the camel.

\section{There is always choice. No matter how heavy the weight of the past, the possibility of existential, commit- ted action remains.}

At this point, in a single page that works as well as anything Marx ever wrote on the subject, Dr. Seuss provides a scathing critique of the division of labor as an ideology of meritocratic hierarchy that legitimates oppression through the pretense of mental superiority. Discovering that he has been doing all the pulling, the weary hero comments, "This is rather unfair." In response, the wubble owner condescendingly explains, "Don't you slew. I am doing my share. / This is called teamwork. I I furnish the brains. I You furnish the muscles, the aches and the pains..." Then true to his word the wubble owner "sat and he worked with bis brain and his tongue / And be bossed me around just because I was young. I He told me go left. Then be told me go right. / And that's what he told me all day and all night."

The next illusion to be shattered is the one of technological dependability. Leaving the wubble owner and the sick camel behind, the young pilgrim tries to take the "Happy Way Bus," which supposedly leaves at exactly "4:42, and will take you directly to Solla Sollew." As it turns out, however, at the bus stop is a sign cheerfully announcing that the $4: 42$ is no longer running, and then adding "But I wish you a most pleasant journey by feet. / Signed / Bus Line President, Horace P. Sweet."

Technological breakdown is followed by natural disaster as the "Midwinter Jicker" pours down torrential 
rain. Our hero floats about aimlessly for twelve days "without toothpaste or soap" and concedes that he had "almost given up bope." At that point he seems to be rescued by a powerful helping hand, but he barely has a chance to say "Thank you, my friend" before he discovers that his friend is really the fascist-looking "General Genghis Kahn Schmitz," who impresses him to serve as the lowliest soldier in his army. The General promises (as we remember being promised so often during the Vietnam War) that "the glorious moment of victory is near!" Nevertheless, the enemy Poozers of Pompelmoose Pass turn out to be far more numerous than expected, and the general finally orders his troops to retreat with the not-so-comforting explanation: "Tbis bappens in war every now and again. / Sometimes you are winners. Sometimes you are losers. / We never can win against so many Poozers

Left to confront the Poozers alone, the protagonist is saved only because he falls down a vent into a strange, surrealistic, bird-filled underground tunnel, suggesting nightmare images of eternal strife, oddly composed of mundane, everyday details of modern life, like bikes, ladders, bottles, campaign signs, and garbage. He becomes a lonely figure struggling upstream against a pressing flow of disconnected, seeping materiality.

Narrowly escaping once again, our hero emerges from below, astonished to discover that he is in front of the door leading to Solla Sollew. With utopia only a step away, he unfortunately learns that exception has become the rule: There are, indeed, almost no troubles in Solla Sollew, but the one little trouble currently in residence is not effectively barring entry through the single available door. Like other idealist visions of perfection, Solla Sollew remains for our pilgrim only imaginary, never real.

\section{Horton finds be must stake bis epi-} stomological ground against mockery, bumiliation, and physical abuse in order to save what he has started to recognize as a voice of real community.

The hero now reaches a moment of existential choice. Declining an opportunity to journey to yet another Promised Land where there are not just few, but no troubles, he chooses instead to go back to where the troubles all began-but not in a spirit of meekness, passivity or resignation. As he recognizes, "I know I'll bave troubles, / I'll maybe get stung, / I'll always bave troubles. / I'll maybe get bit ..." But, in the best tradition of Mao and Che Guevera, he also realizes what one must do in the face of troubles:

"But I've bought a big bat. I'm all ready, you see. Now my troubles are going to have troubles with me!"

W hile I Had Trouble in Getting to Solla Sollew is a story about existential struggle in general, four of Dr. Seuss's books have dealt with familiar and quite specific social issues: Illegitimate hierarchy, racism, ecology, and the arms race. In each, however, Dr. Seuss pushes beyond conventional liberal cliché to offer a more radical version of both the problems and the likelihood of their eventual solution.

One of Dr. Seuss's earliest and most obviously political stories was Yertle the Turtle, written in 1950. Its central theme is hierarchy, which is depicted with stark, corrosive simplicity. Yertle is the turtle king who constructs his throne by requiring his subjects to stack themselves in an ever-higher pile. The weight on the turtles below becomes heavier and heavier as Yertle feeds his arrogant, fantasy rulership of all he can see. Only Mack, the plainest and lowliest of the subjects, dares to voice his opposition: "Your majesty, please... I don't like to complain, / But down here below, we are feeling great pain. I I know, up on top you are seeing great sights, / But down at the bottom we, too, should bave rights."

Finally becoming indignant when he sees the moon rising higher than himself, Yertle announces that he will stack his subjects all the way to heaven. At that point, when the pain becomes unbearable, Mack becomes "a little bit mad," and does a "plain little thing": he burps, and that burp tumbles the whole precarious pile of turtles. Yertle takes a nose dive and is returned to his proper station-resituated in the pond, he is mockingly called "king of the mud," while all the other turtles "are free / As turtles and, maybe, all creatures sbould be."

In Yertle, and in later stories as well, Seuss ruthlessly exposes the artificiality of hierarchy. Oppression is not just evil-it is petty and pointless as well, serving nothing except the self-important delusions of those who rule. As Yertle rises up and his field of vision expands, he proudly (and ludicrously) proclaims:

\footnotetext{
"All mine! ... Oh, the things I now rule!

I'm king of a cow! And I'm king of a mule!

I'm king of a borse! And, what's more, beyond that

I'm king of a blueberry bush and a cat!

I'm Yertle the Turtle! Ob, marvelous me!

For I am the ruler of all that I see!"
} 
Since Yertle's authority is premised on deluded consciousness alone, submission to his oppression is therefore not an act of political necessity, but one of exaggerated fear, so that the oppressed are essentially complicit in their own oppression. The turtles trembled with fear when Yertle "bellowed and brayed" out his orders, and they obeyed. As it turns out, however, they are not nearly as powerless as they felt, for only one slight, whimsical act of opposition is enough to send Yertle's whole structure toppling. The scene at the end is one of joyful frolic, as the turtles happily cavort together in the pond. While Yertle scowls out from under his crown of mud, the others play in a state of anarchic but companionable pleasure.

Yertle the Turtle provides an important lesson about surplus powerlessness, but Mack's burp might have been too easy - a single, slight, contemptuous gesture is sufficient to topple oppression and transform the turtle world into utopia. Nevertheless, in dealing with specific social issues Dr. Seuss became increasingly unwilling to suggest that solutions were easy; as time went on there was a mounting pessimism in his work, combined, however, with a greater sense of urgency in the call for committed moral action.

The Sneetches, written in 1953, a year before Brown v. Board of Education, is an indictment of racism.* In the story Seuss mocks the way in which culturally constructed otherness becomes the basis for oppression. Despite his mocking tone, however, Seuss also recognizes how deeply embedded the construct of otherness is in our culture.

The Sneetches opens by describing a society whose central, organizing principle is domination and subordination based on a supposedly important and natural physical difference: some Sneetches have little stars on their bellies, while others do not. Those with stars maintain their social domination through a process of systematic exclusion:

\section{But, because they had stars, all the Star-Belly \\ Sneetches \\ Would brag, We're the best kind of Sneetch on the beaches \\ With their snoots in the air, they would sniff and \\ they'd snort \\ We'll bave nothing to do with the Plain-Belly sort!}

When the Star-Belly Sneetches had frankfurter roasts Or picnics or parties or marshmallow toasts,

They never invited the Plain-Belly Sneetches

\footnotetext{
*Which is not to suggest that Dr. Seuss is perfect on the question of racism. In If I Ran the Zoo (1950), he failed to rise above his generation, depicting both $A$ sians and $\Lambda$ fricans with racially stereotypic caricature.
}

They left them out cold, in the dark of the beaches. They kept them away. Never let them come near. And that's bow they treated them year after year.

By itself, this description ridicules the insidious social practices based on racism. Dr. Seuss's analysis goes one step further, however. Seuss is not only sensitive to the unjustified self-importance of the excluders, but sensitive as well to its effects on its victims. He understands that the experience of exclusion can push victims to the point of wanting to take on the norms and values of their oppressors, so that they try to deny their own identities in order to pass as dominators. It is that psychic reality of racism, and cultural domination in general, which provides Seuss with a point of departure for a critique that is far more radical than the conventional liberal denunciation of racism as simply not rational or nice.

Seuss bas, in effect, aligned bimself with the anti-authoritarian cat, in order to give children the space they need to make more morally affirmative choices.

In fact, Dr. Seuss introduces a third party who represents a class whose interests might well be served by the perpetuation of racism. In his story, the key character is Sylvester McMonkey McBean, a predatory and exploitative entrepreneur who plays skillfully on the fears and anxieties of the Sneetch victims who are caught up in the racist world view of their oppressors.

For three dollars each, McBean, with a very large machine, transforms the Sneetches without stars into creatures indistinguishable from their former oppressors. Confronted with the abolition of physical difference, the original Star-Belly Sneetches desperately proclaim, "We're still the best Sneetches and they are the worst, / But now bow in the world will we know... I If which kind is what, or the other way round?" McBean, looking as sleazy as can be, now charging $\$ 10$ each and using a fancier machine, removes the stars from the bellies of the original oppressors. Next, of course, McBean offers to remove the stars he has sold to the original victims. As this selling process escalates, the scene turns into an orgy of capitalist exploitation, with constant streams of Sneetches paying to enter one machine to be starred and then to enter another to be unstarred, while McBean stands grinning in the center, in front of an ever-growing mountain of cash.

(Contimued on p. 113) 


\section{DR. SEUSS}

The chaos ends when the Sneetches all run out of money, and McBean, with capitalist complacency, laughs as he leaves, noting, "They never will learn. No, you can't teach a Sneetch!"

Nevertheless, The Sneetches ends on a note that is at least slightly hopeful. Having been so fully and relentlessly exploited, the Sneetches manage to achieve a consciousness breakthrough that obliterates the racism of their culture:

But McBean was quite wrong. I'm quite happy to say That the Sneetches got really quite smart on that day, The day they decided that Sneetches are Sneetches And no kind of Sneetch is the best on the beaches.

That Sneetch recognition of shared victimization, however, came only after the complete economic destruction of Sneetch society. Having been reduced to common economic powerlessness, the Sneetches finally realize a unitary class consciousness.

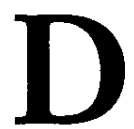

r. Seuss's book about environmental destruction, The Lorax, is more dark and despairing in mood, with only the slightest glimmer of hope at the end. As in The Sneetches, a prevailing and destructive ideology takes hold and becomes utterly totalizing. In The Lorax, visual imagery intensifies the bleakness of mood, as even the once proud capitalist, now a miserable and guilty hermit, despairs at the wasteland produced by his own pursuit of gain. Colors are dark blues, grays, purples, and browns, and the only visible vegetation is an occasional thin strand of stiff Grickle-grass.

The ideological mainstay demolished by The Lorax is a basic one: Market Freedom. According to conventional wisdom, in a free economy bright entrepreneurs discover novel techniques for fashioning from raw materials new products for the satisfaction of authentic 
human needs, which are expressed through choice and exchange on a free market. In Seuss's account the extraction of raw materials becomes the rape of the natural world, as an entire species of trees (the Truffula Trees) is destroyed, along with the fragile ecosystem of birds, animals, and fish that once depended on it. This destruction is accompanied by the pollution which is the inevitable by-product of manufacture.

Meanwhile, the product whose manufacture requires this wholesale devastation of the environment makes a mockery of the market ideologies of both need and utility. The Thneed, claiming to be everything useful, is in fact nothing but a representation of the artificiality of consumer demand as created and manipulated by the greedy producer. The capitalist at first defensively claims universal utility for his new product ("A Thneed's a Fine Something-That-All-People-Need / It's a shirt. It's a sock. It's a glove. It's a bat ... You can use it for carpets. For pillows! For sheets! / Or curtains! Or covers or bicycle seats!") Nevertheless, even he wryly observes after his first sale: "You never can tell what some people will buy."

Despite this early self-awareness, the capitalist is quickly captured by his own ideological role as acquisitive accumulator, to the point where production, which at least in theory should be a function of rational economic planning, becomes an obsessive and irrational felt necessity. Thus, he at first "felt sad" when the frolicsome, little bear-like creatures, the Bar-ba-loots, were forced to leave because they could not live without Truffula Fruit, although he quickly convinces himself:

"But ... business is business

And business must grow... I meant no harm.

I most truly did not.

But I had to grow bigger. So bigger I got.

I biggered my factory. I biggered my roads.

I biggered my wagons. I biggered the loads

Of the Thneeds I shipped out, I was shipping them forth

to the South! To the East! To the West! To the North! I went right on biggering ... selling more Thneeds. And I biggered my money, which everyone needs."

With capitalist and consumer alike caught up in the totalizing culture of greed, acquisition, and gratification, the possibility of critique from within is remote if not lost. The sole critical voice is that of the Lorax, a wizened elfish being who seems to antedate JudeoChristian culture and take us back to a world where nature could speak for itself and be heard. Akin to a Druidic spirit, he emerges from a tree to scold the foolish capitalist and by extension any culture which in its self-importance thinks it can stand apart from its 